\section{Reclaiming our taxonomic umwelt: a book review}

\section{Rajith Dissanayake}

Department of Zoology, The Natural History Museum, Cromwell Road, London SW7 5BD, United Kingdom Email: rajith@clara.co.uk

The history and rationale of scientific taxonomy, has been covered in grandly titled works like Classification, Evolution and the Nature ofBiologyby Panchen. But do we have any stake in it, as biodiversity disappears? The subtitle of author Carol Kaesuk Yoon's rambunctious exploration better reveals her radical thrust.

We are ever reliant on best selling field guides to showcase biodiversity and its representative species although the species concept has proven

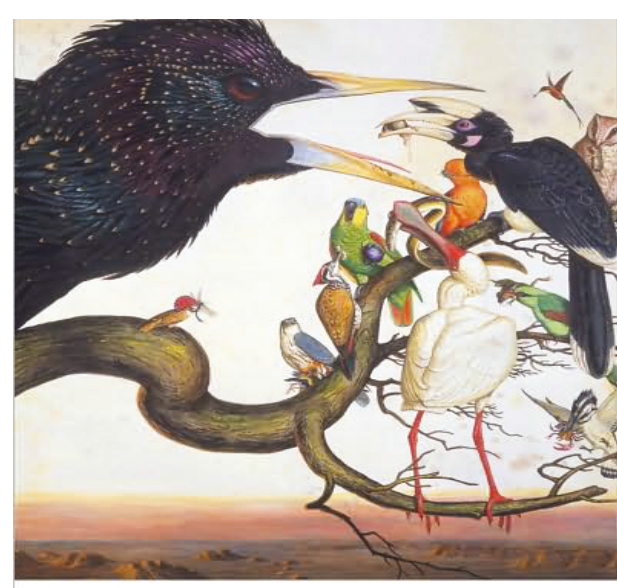

\section{NAMING NATURE}

THE CLASH BETWEEN INSTINCT AND SCIENCE

CAROL KAESUK YOON

2009, Norton, New York, 344pp., \$28 SBN 9780393061970

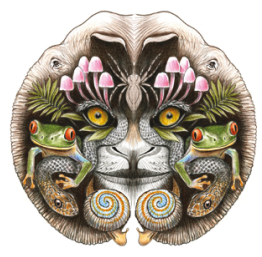

evolution explained its underpinning.

Darwin cut his taxonomic teeth over "eight gruelling years" on barnacles but the eventual "revelation of evolution was no clarifying gift to taxonomy" as Darwin had assumed.

Taxonomic work couched within Darwinism remained relatively unchanged though "[20th century evolutionary] Taxonomy had undergone one dramatic change however. It was now entirely the territory, the sole property of the professional taxonomists. ... No longer did the ordering of any particular living thing seem to capture the interest of anyone outside the confines of an increasingly limited group of specialists." Headed by giants like elusive "as each [biologist] tried endlessly to patch his ... deflating definition [of a species], to what ... has been absolutely no good end." Darwin's reiteration from a private letter still stands: "the opinion of naturalists having sound judgement and wide experience seems the only guide to follow ... this may not be a cheering prospect, but we shall at least be freed from the vain search for the undiscovered and undiscoverable essence of the term species." (Schilthuizen M., Frogs Flies \& Dandelions, The Making of Species) As child naturalists, we probably recognized species guided by our primeval umwelt, a perceived sense of the natural world, but have ended up deferring to science to explain it. Yoon begins by broaching the consequences of taxonomic systems that have eliminated "fish" and zebras as real categories while three species disappear per hour, "1,000 times the rate ... they were disappearing before humanity" often eliciting a collective yawn. Why? Yoon wants her fish back.

In 1735, Linnaeus' fourteen page Systema Naturae

Date of publication (online): 26 July 2010

Date of publication (print): 26 July 2010

ISSN 0974-7907 (online) | 0974-7893 (print)

Reviewer: Rajith Dissanayake (PhD, MSc, FZS, FLS) is an unpaid taxonomist focussing on Oriental biodiversity currently employed at Birkbeck College, University of London. His PhD thesis, A taxonomic revision of Funambulus (Rodentia: Sciuridae) is due to be published by Lambert Academic Publishing shortly.

\section{OPEN ACCESS I FREE DOWNLOAD (C) (i) ৫)}

Mayr, taxonomic vindication retained a certain subjectivity as quoted from Mayr and Amadon: "No one believes any longer that the pipits or 'tit-larks' are related to the true larks." There were always the debates between lumpers and splitters, but Mayr realised species were real, when his identification of 137 species of New Guinean birds of paradise was corroborated by Arfak tribesmen who recognized 136 .

Perhaps both Mayr and the Arfak people relied on an instinct that even animals share. Classifying nature is a multifarious survival trait such as differentiating between food and non-food. Yoon expands upon a wealth of evidence such as cases of brain damage where people have lost the ability to name organisms but retain the we can correctly differentiate between birds or fish just by listening to novel pairings of unfamiliar names from obscure tribal sources, e.g., which of the following is a bird, a yawarach or tuikcha? Indeed, there seems to be a limit to how many genera trained naturalists can easily recall to around 600 that influences our nomenclatural systems.

Traditional, authoritative if subjective taxonomy as practiced by Mayr did not amount to experimental science. The separation between taxonomy and science "went much deeper than a mere two centuries of tradition. [They] were devoted to a tradition as ancient as humanity ... the vision of their umwelt."

The objectification of taxonomy into science took the routes of numerical, molecular and cladistic approaches, capacity to name inanimate objects. She indicates how 
each parcelled within separate chapters. Increasingly, taxonomy was an exercise in selecting branches off phylogenies of growing abstraction. The cladists in particular had divorced us from the umwelt. Whereas a child will sense the pairing between a salmon and a lungfish against a cow, the cladist will disagree.

Cladistics triumphed in the 1980s, as biodiversity loss hit the headlines. "How could it be, [asked biologists] ... in soul-searching seminars ... that people cared so little about the living world?" Yoon's explanation is somewhat startling: "science has slowly but surely distanced itself from the view of the living world that all ... share and understand" leaving us blind to our own view of it. Not surprisingly there is little funding for taxonomy. Curatorial staff are eliminated as they become as endangered as some of the species they studied. University departments dedicated to the living world become absorbed into biomedicine.

Equally real taxonomists such as the Tzeltal Maya of Mexico however do remain where toddlers can name thirty plant species. Ironically, many such tribal communities and their practical knowledge of medicines and food are also threatened whereas our general umwelt is spent on consumer brands and childhood intimacies with dinosaurs and Pokemon.
Yoon stresses that we have to reclaim all our taxonomies given that nature is a collective and priceless property: "the sooner we get back our original vision the better."

Her conclusions are evidenced for example in noting the current, relatively specialised volumes of periodicals such as the Journal of the Bombay Natural History Society that towards the first half of the twentieth century burgeoned with information from amateurs and specialists including "sportsmen", soldiers, civil servants and paid naturalists. Confined as many of these journals now are to strictly peer reviewed output, it can take up to a year to publish one species description during which time 50,000 may have disappeared. The available manpower and interest is less than scarce. Most laymen get very little say and forums for their observations to make a difference remain limited. Naming Nature could be the vehicle of a revolution or at least a revival in understanding and reclaiming traditional and folk taxonomies for wider appreciation in contrast to a highly expensive, abstruse science based methodology that has arguably succeeded in putting itself out of business. 